\title{
The feasibility of shear wave elastography for diagnosing superficial benign soft tissue masses
}

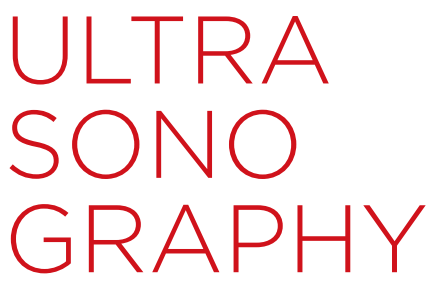

\author{
Hyun Jung Yeoh', Tae-Yoon Kim², Jeong Ah Ryu² \\ ${ }^{1}$ Department of Radiology, Hanyang University Hospital, Seoul; ' Department of Radiology, \\ Hanyang University Guri Hospital, Guri, Korea
}

\section{ORIGINAL ARTICLE}

https://doi.org/10.14366/usg. 17059 pISSN: 2288-5919 - elSSN: 2288-5943 Ultrasonography 2019;38:37-43

Purpose: The purpose of this study was to investigate the feasibility of shear wave ultrasound elastography for differentiating superficial benign soft tissue masses through a comparison of their shear moduli.

Methods: We retrospectively analyzed 48 masses from 46 patients from February 2014 to May 2016. Surgical excision, fine-needle aspiration, and clinical findings were used for the differential diagnosis. The ultrasonographic examinations were conducted by a single musculoskeletal radiologist, and the ultrasonographic findings were reviewed by two other radiologists who were blinded to the final diagnosis. Conventional ultrasonographic features and the median shear modulus were evaluated. We compared the median shear moduli of epidermoid cysts, ganglion cysts, and lipomatous tumors using the Kruskal-Wallis test. Additionally, the Mann-Whitney U test was used to compare two distinct groups.

Results: Significant differences were found in the median shear moduli of epidermoid cysts, ganglion cysts, and lipomatous tumors $(23.7,5.8$, and $9.2 \mathrm{kPa}$, respectively; $P=0.019)$. Epidermoid cysts showed a greater median shear modulus than ganglion cysts $(P=0.014)$ and lipomatous tumors $(\mathrm{P}=0.049)$.

Conclusion: Shear wave elastography may contribute to the differential diagnosis of superficial benign soft tissue masses through a direct quantitative analysis.

Keywords: Shear strength; Elasticity imaging techniques; Elastic modulus; Epidermal cyst; Ganglion cysts; Lipoma

Received: September 5, 2017

Revised: January 15, 2018

Accepted: January 19, 2018

Correspondence to: Jeong Ah Ryu, MD, Department of Radiology, Hanyang University Guri Hospital, 153 Gyeongchun-ro, Guri 11923, Korea

Tel. $+82-31-560-2449$

Fax. +82-31-560-2551

E-mail: ryuja@hanyang.ac.kr

\begin{abstract}
This is an Open Access article distributed under the terms of the Creative Commons Attribution NonCommercial License (http://creativecommons.org/ licenses/by-nc/3.0/) which permits unrestricted noncommercial use, distribution, and reproduction in any medium, provided the original work is properly cited.
\end{abstract}

Copyright (c) 2019 Korean Society of Ultrasound in Medicine (KSUM)

\section{Introduction}

Ultrasonography has the advantages of being widely available, cost-effective, and allowing real-time dynamic examinations. Additionally, it is less time-consuming than magnetic resonance imaging (MRI) $[1,2]$. Superficial lesions of the musculoskeletal system can be visualized with much higher resolution by ultrasonography than by MRI $[1,2]$.

Recently developed ultrasound elastography techniques provide valuable information about intrinsic tissue properties by evaluating tissue elasticity, which may contribute to the diagnosis $[3,4]$. Shear wave elastography (SWE) can quantify tissue elasticity and add important information to the

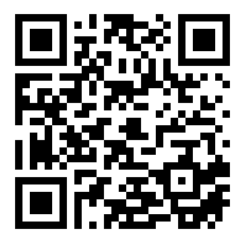

How to cite this article:

Yeoh HJ, Kim TY, Ryu JA. The feasibility of shear wave elastography for diagnosing superficial benign soft tissue masses. Ultrasonography. 2019 Jan;38(1):37-43. 
findings obtained by conventional ultrasonography $[3,5-7]$. SWE has been approved by the U.S. Food and Drug Administration for most high-end ultrasonographic devices by several advanced vendors for diagnostic imaging of the musculoskeletal system $[3,5]$. SWE is considered to be highly clinically useful for musculoskeletal imaging [6-11].

Several studies have explored the application of sonoelastography for superficial soft tissue masses $[9,11-14]$. The most recent study suggested that malignant soft tissue lesions show variable elasticity according to cellular differentiation and tissue characteristics. Therefore, more studies should be done to identify ways of differentiating malignant soft tissue tumors from benign tumors [11-14]. However, most soft tissue tumors are benign lesions. In other words, it is more likely that clinicians will encounter benign soft tissue tumors. Therefore, we thought that it would be worthwhile to use SWE to acquire additional information about a tumor, beyond its morphology, without spending much additional time. We have become interested in whether the histologic features of benign soft tissue tumors affect their elasticity. We investigated the elasticity of superficial benign masses to assess the feasibility of SWE as a supplementary tool to conventional sonography.

\section{Materials and Methods}

The Institutional Review Board of Hanyang University Guri Hospital approved this retrospective study (2017-07-019), and the requirement for informed consent was waived.

\section{Patient Selection}

This study analyzed patients who received care at our institution from February 2014 to May 2016. Of these 86 patients with 102 benign-appearing soft tissue masses, 40 were not followed up to obtain a final diagnosis. Therefore, 48 lesions from 46 patients were included in this study. We retrospectively investigated patients' medical records, ultrasonographic exams, and histopathology reports in March 2017. The study included 24 males and 22 females, with a mean age of 49.8 years (range, 17 to 79 years).

\section{Ultrasonographic Examinations}

For each lesion, SWE was performed, in addition to grayscale and Doppler ultrasound on the same day. For consistency, all ultrasonographic examinations were conducted by a single musculoskeletal radiologist with 16 years of experience, using a commercially available Aixplorer ultrasound system (SuperSonic Imagine, Aix en Provence, France) and a 4-15 MHz linear array transducer.

The transducer was perpendicular to the lesion and stationary, without external compression. Grayscale images and color-coded elastograms were displayed with dual-mode imaging in real time (Fig. 1). In the chromatic scale, red indicated a higher shear modulus than blue.

Several circular regions of interest (ROIs) with a diameter of 2 or

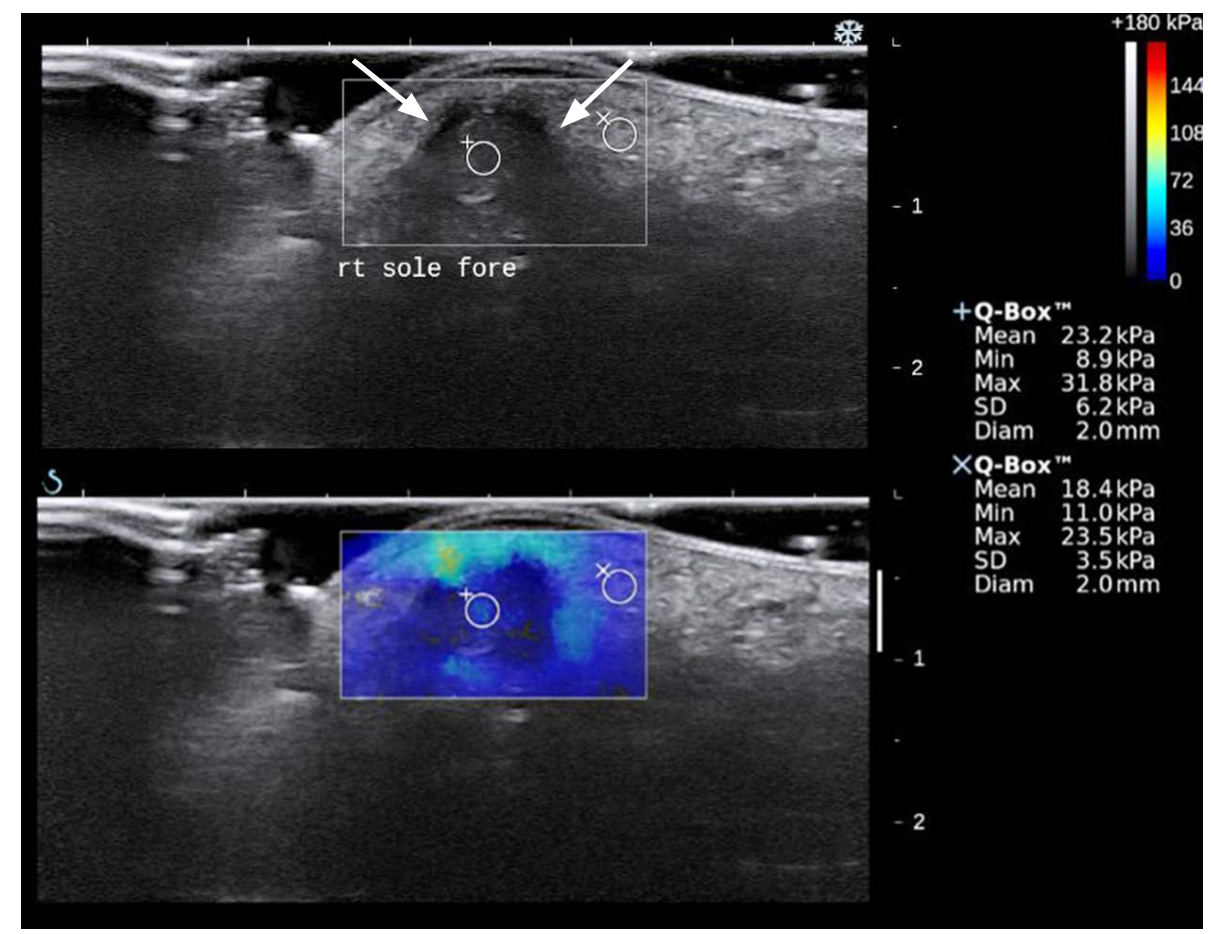

Fig. 1. Epidermoid cyst in the forefoot of a 17-year-old man. Grayscale ultrasonography (upper) shows a wellcircumscribed hypoechoic nodule (arrows) in the subcutaneous layer. Shear wave elastography (lower) shows that the mean shear modulus corresponding to the region of interest was $23.2 \mathrm{kPa}$. 
$3 \mathrm{~mm}$ were placed within the lesion. The mean shear modulus for each ROI was measured automatically. We calculated the median value of several mean shear moduli corresponding to the ROls, and this value was defined as the median shear modulus of the lesion. The unit of shear modulus values was the kilopascal ( $\mathrm{kPa}$ ).

\section{Review of Ultrasonographic Images}

A certified radiologist with 1 year of experience and a radiology resident reviewed the images by consensus, without information about the final diagnosis. We assessed conventional ultrasonographic features, including location, size $(\mathrm{mm})$, depth $(\mathrm{mm})$, margin (welldefined or ill-defined), echogenicity (hypoechoic, hyperechoic, isoechoic, or anechoic compared to muscle), and vascularity (absent or present). The conventional ultrasonographic features and the median shear modulus were documented according to the final diagnosis.

\section{Statistical Analysis}

SPSS version 18.0 (SPSS Inc., Chicago, IL, USA) was used for all statistical analyses. Non-parametric tests were carried out for the median shear modulus values. For statistical significance testing, we classified lesions according to the final diagnosis as epidermoid cysts, ganglion cysts, lipomatous tumors, or miscellaneous lesions. We compared the median shear moduli of epidermoid cysts, ganglion cysts, and lipomatous tumors using the Kruskal-Wallis test. Additionally, the Mann-Whitney $\mathrm{U}$ test was used to compare two distinct groups. P-values of $<0.05$ were considered to indicate a significant difference.

\section{Results}

\section{Final Diagnosis of Benign Soft Tissue Masses}

The histopathologic diagnosis was made after surgical excision for 33 lesions and fine needle aspiration for five lesions. The final diagnoses of 10 lesions (7 ganglion cysts, 1 lipoma, 1 lymph node, and 1 panniculitis) were based on characteristic findings of sonography and clinical assessment that are widely accepted in clinical practice. An ill-defined hyperechoic lesion of the abdominal wall after blunt trauma was clinically diagnosed as traumatic panniculitis. The 48 lesions comprised six epidermoid cysts, 15 ganglion cysts, 16 lipomatous tumors, and 11 miscellaneous lesions. The lipomatous tumors included 14 lipomas and two angiolipomas. The miscellaneous lesions included two arteriovenous malformations, two cases of panniculitis, one cavernous hemangioma, one

Table 1. Conventional ultrasonographic features according to the diagnosis

\begin{tabular}{|c|c|c|c|c|}
\hline $\begin{array}{c}\text { Conventional } \\
\text { ultrasonographic feature }\end{array}$ & $\begin{array}{l}\text { Epidermoid cyst } \\
\qquad(\mathrm{n}=6)\end{array}$ & $\begin{array}{l}\text { Ganglion cyst } \\
(n=15)\end{array}$ & $\begin{array}{l}\text { Lipomatous tumor } \\
\qquad(n=16)\end{array}$ & $\begin{array}{c}\text { Miscellaneous lesion } \\
(n=11)\end{array}$ \\
\hline \multicolumn{5}{|l|}{ Location } \\
\hline Upper extremity & $2(33.3)$ & $9(60)$ & $3(18.8)$ & $4(36.4)$ \\
\hline Lower extremity & $2(33.3)$ & $6(40)$ & $3(18.8)$ & $4(36.4)$ \\
\hline Trunk & $2(33.3)$ & 0 & $9(56.3)$ & $3(27.3)$ \\
\hline Neck & 0 & 0 & $1(6.3)$ & 0 \\
\hline \multicolumn{5}{|l|}{ Depth (mm) } \\
\hline Mean $\pm S D$ & $1.92 \pm 1.04$ & $2.22 \pm 0.85$ & $4.18 \pm 3.14$ & $3.55 \pm 4.25$ \\
\hline Range & $0.7-3.0$ & $1.0-4.0$ & $1.4-14.0$ & $0.5-13.0$ \\
\hline \multicolumn{5}{|l|}{ Margin } \\
\hline Well-defined & $5(83.3)$ & $14(93.3)$ & $14(87.5)$ & $8(72.7)$ \\
\hline III-defined & $1(16.7)$ & $1(6.7)$ & $2(12.5)$ & $3(27.3)$ \\
\hline \multicolumn{5}{|l|}{ Echogenicity } \\
\hline Hypoechoic & $4(66.7)$ & $5(33.3)$ & $9(56.3)$ & $8(72.7)$ \\
\hline Hyperechoic & $1(16.7)$ & 0 & $2(12.5)$ & $3(27.3)$ \\
\hline Isoechoic & $1(16.7)$ & 0 & $5(31.3)$ & 0 \\
\hline Anechoic & 0 & $10(66.7)$ & 0 & 0 \\
\hline \multicolumn{5}{|l|}{ Vascularity } \\
\hline Absent & $6(100)$ & $15(100)$ & $11(68.8)$ & $2(18.2)$ \\
\hline Present & 0 & 0 & $5(31.3)$ & $9(81.8)$ \\
\hline
\end{tabular}

Values are presented as number (\%) unless otherwise indicated.

SD, standard deviation. 
thrombosed pseudoaneurysm, one schwannoma, one neurofibroma, one vascular leiomyoma, one foreign body granuloma, and one lymph node.

\section{Conventional Ultrasonographic Features}

All lesions were visually assessed using grayscale and Doppler ultrasound (Table 1). All ganglion cysts were located in the upper or lower extremities, while $56.3 \%(n=9)$ of the lipomatous tumors were located in the trunk. The mean depth of the lipomatous tumors was the greatest, at $4.18 \mathrm{~mm}$. A circumscribed margin was present in $85.4 \%(n=41)$ of all lesions. The majority $(66.7 \%, n=4)$ of the epidermoid cysts were hypoechoic, and $66.7 \%(n=10)$ of the ganglion cysts were anechoic. Of the lipomatous tumors, $56.3 \%$ $(n=9)$ were hypoechoic and $31.3 \%(n=5)$ were isoechoic. None of the epidermoid cysts or ganglion cysts had vascularity, while $31.3 \%(n=5)$ of the lipomatous tumors and the $81.8 \%(n=9)$ of the miscellaneous lesions had internal vascularity.

\section{Quantitative Analysis of Shear Modulus}

The SWE findings of the superficial benign soft tissue masses overlapped to some extent (Figs. 1-4). The median shear modulus was $23.7 \mathrm{kPa}$ for the epidermoid cysts, $5.8 \mathrm{kPa}$ for the ganglion cysts, and $9.2 \mathrm{kPa}$ for the lipomatous tumors (Table 2). There were significant differences among the epidermoid cysts, ganglion cysts, and lipomatous tumors ( $P=0.019)$. The epidermoid cysts yielded the highest median shear modulus and the widest range of shear modulus values (Fig. 5). The median shear modulus of the epidermoid cysts was greater than that of the ganglion cysts $(P=0.014)$. Moreover, the median shear modulus of the epidermoid cysts was greater than that of the lipomatous tumors $(P=0.049)$. However, there was no significant difference between the

Table 2. Median shear modulus according to the diagnosis

\begin{tabular}{lcc}
\hline \multicolumn{1}{c}{ Diagnosis } & No. & $\begin{array}{c}\text { Median shear modulus } \\
(\mathrm{kPa})\end{array}$ \\
\hline Epidermoid cyst & 6 & $23.7 \pm 15.5(3.9-40.8)^{\mathrm{a})}$ \\
Ganglion cyst & 15 & $5.8 \pm 5.2(0-18.1)^{\mathrm{a})}$ \\
Lipomatous tumor & 14 & $9.2 \pm 5.3(2.3-17.6)^{\mathrm{a})}$ \\
$\quad$ Lipoma & 2 & - \\
$\quad$ Angiolipoma & & \\
Miscellaneous lesions & 2 & $0,4.3$ \\
Arteriovenous malformation & 2 & $14.2,21.1$ \\
Panniculitis & 1 & 30.9 \\
Cavernous hemangioma & 1 & 20.6 \\
Thrombosed pseudoaneurysm & 1 & 5.9 \\
Schwannoma & 1 & 16.5 \\
Neurofibroma & 1 & 24.2 \\
Vascular leiomyoma & 1 & 28.3 \\
Foreign body granuloma & 1 & 8.2 \\
Lymph node & &
\end{tabular}

${ }^{a)}$ Values are presented as mean \pm standard deviation (range).

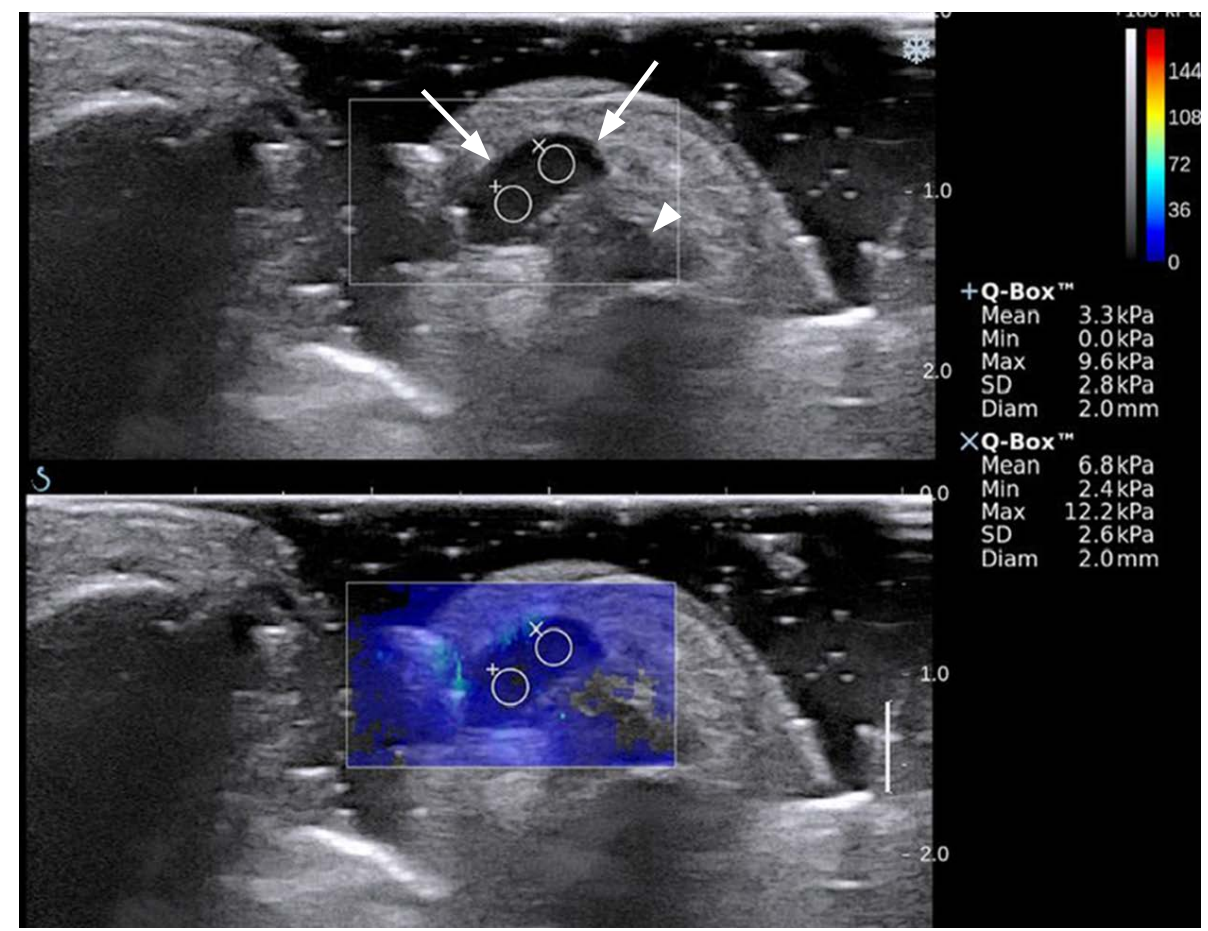

Fig. 2. A ganglion cyst in the third proximal phalanx of a 74-year-old woman. Grayscale ultrasonography (upper) shows a well-circumscribed hypoechoic nodule (arrows) connected to the flexor tendon (arrowhead). Shear wave elastography (lower) shows that the mean shear moduli corres-ponding to the regions of interest were 3.3 and $6.8 \mathrm{kPa}$. 
lipomatous tumors and ganglion cysts $(\mathrm{P}=0.101)$. Three ganglion cysts and one miscellaneous lesion (an arteriovenous malformation) did not create sufficient shear waves, so the shear modulus of these lesions was zero or less than 0.5 .

\section{Discussion}

The radiologic diagnosis of soft tissue tumors is challenging. Conventional ultrasonography cannot differentiate malignancies from benign lesions despite its excellent resolution, so a biopsy is ultimately required to establish a diagnosis and plan the
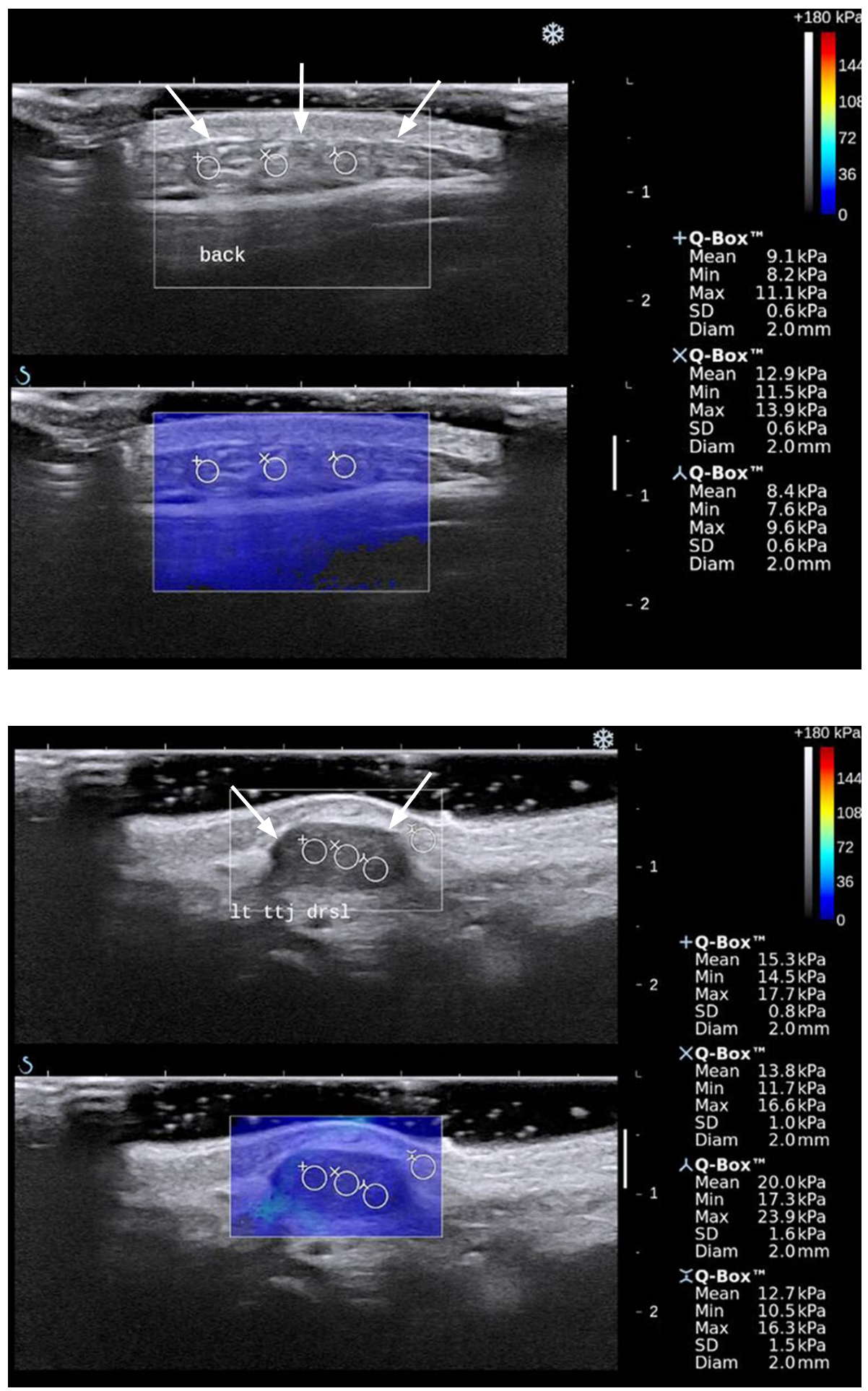

Fig. 3. Lipoma in the mid-back of a 48-year-old woman. Grayscale ultrasonography (upper) shows a well-circumscribed isoechoic mass (arrows) below the dermis. Shear wave elastography (lower) shows that the mean shear moduli corresponding to the regions of interest were $9.1,12.9$, and $8.4 \mathrm{kPa}$.
Fig. 4. Neurofibroma in the dorsal aspect of the tibiotalar joint in a 70-year-old woman. Grayscale ultrasonography (upper) shows a well-circumscribed hypoechoic nodule (arrows) in the subcutaneous layer. Shear wave elastography (lower) shows that the mean shear moduli corresponding to the regions of interest were $15.3,13.8$, and $20.0 \mathrm{kPa}$. 


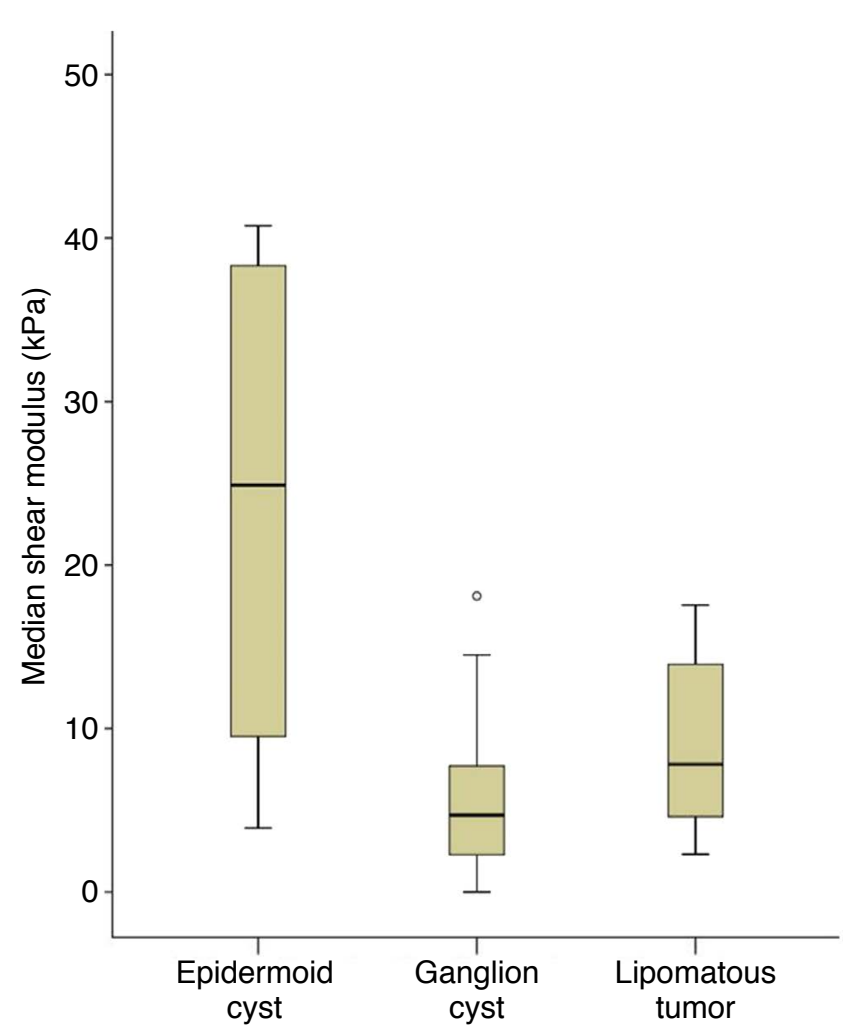

Fig. 5. Differences of the median shear modulus according to the diagnosis. The box plot shows the median shear modulus values of epidermoid cysts, ganglion cysts, and lipomatous tumors ( $P=0.019$, Kruskal-Wallis test). The open dot represents an outlier.

management [13]. Furthermore, the echogenicity of lipomas depends on the amount and purity of the fatty tissue and water components $[15,16]$.

SWE uses different physical principles from those used strain elastography $[3,17]$. Shear waves are generated within the tissue when conventional ultrasound waves produced by a transducer interact with the tissue $[8,17]$. This technique allows the operator to view the color-coded elastogram and to measure the shear modulus $(\mathrm{kPa})$ or shear wave velocity $(\mathrm{m} / \mathrm{sec})$. SWE is not affected by the operator's external force and does not need a reference for quantification, unlike strain elastography.

In principle, if a medium is composed of pure liquid, the shear velocity will be zero because shear waves are not transferred to pure water [18]. However, most cystic tumors have some degree of elasticity. This result may suggest that either the inside of the cyst wall is semisolid or that the shear wave signals contain artifacts. Another possibility is viscosity. In our study, epidermoid cysts, which are thought to be composed of a viscous substance, had a higher shear modulus than other cystic lesions [19]. The contrast of elastography decreases with increasing vibration frequency, and shear viscosity is important in evaluating liver elasticity. Most ultrasound elastography techniques, however, overlook the effects of viscosity in the assessment of shear modulus [20].

Only a few studies have addressed the elasticities of ganglion cysts and epidermoid cysts [9]. In a study using strain elastography, ganglion cysts showed a higher strain ratio $(2.78 \pm 0.48)$ than epidermoid cysts $(0.17 \pm 0.21)$ [9]. This means that that ganglion cysts are more compressible and epidermoid cysts are firmer, which is consistent with our results.

In this study, there was a case of a ruptured epidermoid cyst. The median shear modulus of the ruptured epidermoid cyst was $3.9 \mathrm{kPa}$ lower than that of the other epidermoid cysts. Considering that the median shear modulus of panniculitis or foreign body granulomas is relatively high, this result may have been due to the acute phase of the lesion involving decreased internal tension.

Although no statistically significant difference was found between ganglion cysts and lipomatous tumors, it is possible to distinguish these lesions using conventional ultrasonography. This result shows that the elasticity of solid lesions can be similar to that of cystic lesions.

In studies of musculoskeletal tumors, malignant tumors have been found to have lower shear velocities $[11,12]$. However, another study found that this tendency was not discriminatory, as all color groups contained benign and malignant tumors $[13,14]$. Bhatia et al. [21] showed that among masses of the neck, the stiffness was high for neurogenic tumors or neuromas, dermoid cysts, and metastatic tumors, while the stiffness was low for lipomas, lymphatic and/or venous malformations, and cystic tumors [5].

This study had the limitation of only targeting benign tumors. We chose to focus on the biochemical properties of benign soft tissue tumors because softest tissue tumors are benign. In the United States, the annual incidence of soft tissue tumors is about three cases out of every 1,000 people, of which $0.67 \%$ are malignant [22]. However, because the subjects were not recruited in a consecutive manner, selection bias was inevitable. In addition, making the differential diagnosis of a benign tumor under circumstances in which a malignant tumor cannot be ruled out can lead to serious errors. Because our institution did not have a sufficient number of malignant cases to reach statistical significance, a large multicenter study is needed to increase the value of this preliminary study.

Likewise, because of the small population size, we were unable to evaluate various types of soft tissue tumors and to determine a significant cutoff value for differentiating between ganglion cysts and epidermoid cysts. Finally, the shear modulus values that we measured cannot be applied to different equipment, as we used only one kind of instrument and probe for SWE.

Choi et al. [23] proposed that the elasticity of lipomas differs 
in intramuscular and subcutaneous lesions. Thus, even though tumors have the same histologic composition, their elasticity can vary depending on their location. In particular, the distance from surface or bone and the effects of arterial pulsation can change the elasticity of the lesion. This study did not consider these issues, and subsequent studies will be needed to investigate them. Additionally, research using excised specimens will allow us to understand the direct influence of histologic features on mass elasticity.

In conclusion, we found the highest shear modulus values for epidermoid cysts, followed by lipomatous tumors and ganglion cysts. This study demonstrates the value of the direct quantitative analysis of superficial benign soft tissue masses using SWE.

ORCID: Hyun Jung Yeoh: https://orcid.org/0000-0003-3427-9022; Tae-Yoon Kim: https://orcid.org/0000-0001-8392-1822; Jeong Ah Ryu: https://orcid.org/0000-00024474-180X

\section{Conflict of Interest}

No potential conflict of interest relevant to this article was reported.

\section{References}

1. Jacobson JA, Wilson TJ, Yang LJ. Sonography of common peripheral nerve disorders with clinical correlation. J Ultrasound Med 2016:35:683-693.

2. Ryu JA, Lee SH, Cha EY, Kim TY, Kim SM, Shin MJ. Sonographic differentiation between schwannomas and neurofibromas in the musculoskeletal system. J Ultrasound Med 2015;34:2253-2260.

3. Drakonaki EE, Allen GM, Wilson DJ. Ultrasound elastography for musculoskeletal applications. Br J Radiol 2012;85:1435-1445.

4. Taljanovic MS, Gimber LH, Becker GW, Latt LD, Klauser AS, Melville DM, et al. Shear-wave elastography: basic physics and musculoskeletal applications. Radiographics 2017;37:855-870.

5. Klauser AS, Miyamoto H, Bellmann-Weiler R, Feuchtner GM, Wick MC, Jaschke WR. Sonoelastography: musculoskeletal applications. Radiology 2014;272:622-633.

6. Ryu J, Jeong WK. Current status of musculoskeletal application of shear wave elastography. Ultrasonography 2017;36:185-197.

7. Lima K, Costa Junior JF, Pereira WC, Oliveira LF. Assessment of the mechanical properties of the muscle-tendon unit by supersonic shear wave imaging elastography: a review. Ultrasonography 2018;37:3-15.

8. Bamber J, Cosgrove D, Dietrich CF, Fromageau J, Bojunga J, Calliada $F$, et al. EFSUMB guidelines and recommendations on the clinical use of ultrasound elastography. Part 1: Basic principles and technology. Ultraschall Med 2013;34:169-184.

9. Lee YH, Song HT, Suh JS. Use of strain ratio in evaluating superficial soft tissue tumors on ultrasonic elastography. J Med Ultrason (2001) 2014;41:319-323.

10. Kim SJ, Park HJ, Lee SY. Usefulness of strain elastography of the musculoskeletal system. Ultrasonography 2016;35:104-109.

11. Park HJ, Lee SY, Lee SM, Kim WT, Lee S, Ahn KS. Strain elastography features of epidermoid tumours in superficial soft tissue: differences from other benign soft-tissue tumours and malignant tumours. $\mathrm{Br}$ J Radiol 2015;88:20140797.

12. Magarelli N, Carducci C, Bucalo C, Filograna L, Rapisarda S, De Waure $\mathrm{C}$, et al. Sonoelastography for qualitative and quantitative evaluation of superficial soft tissue lesions: a feasibility study. Eur Radiol 2014;24:566-573.

13. Pass B, Jafari M, Rowbotham E, Hensor EM, Gupta H, Robinson P. Do quantitative and qualitative shear wave elastography have a role in evaluating musculoskeletal soft tissue masses? Eur Radiol 2017;27:723-731.

14. Pass B, Johnson M, Hensor EM, Gupta H, Robinson P. Sonoelastography of musculoskeletal soft tissue masses: a pilot study of quantitative evaluation. J Ultrasound Med 2016;35:2209-2216.

15. Behan M, Kazam E. The echographic characteristics of fatty tissues and tumors. Radiology 1978;129:143-151.

16. Gritzmann N, Schratter M, Traxler M, Helmer M. Sonography and computed tomography in deep cervical lipomas and lipomatosis of the neck. J Ultrasound Med 1988;7:451-456.

17. Bercoff J, Tanter M, Fink M. Supersonic shear imaging: a new technique for soft tissue elasticity mapping. IEEE Trans Ultrason Ferroelectr Freq Control 2004;51:396-409.

18. Slapa RZ, Kasperlik-Zaluska AA, Migda B, Jakubowski WS. Shear wave elastography of adrenal masses is feasible and may help to differentiate between solid and cystic lesions: an initial report. Endokrynol Pol 2014;65:119-124.

19. Bhatia KS, Yuen EH, Cho CC, Tong CS, Lee YY, Ahuja AT. A pilot study evaluating real-time shear wave ultrasound elastography of miscellaneous non-nodal neck masses in a routine head and neck ultrasound clinic. Ultrasound Med Biol 2012;38:933-942.

20. Bercoff J, Tanter M, Muller M, Fink M. The role of viscosity in the impulse diffraction field of elastic waves induced by the acoustic radiation force. IEEE Trans Ultrason Ferroelectr Freq Control 2004;51:1523-1536.

21. Bhatia KS, Rasalkar DD, Lee YP, Wong KT, King AD, Yuen YH, et al. Real-time qualitative ultrasound elastography of miscellaneous non-nodal neck masses: applications and limitations. Ultrasound Med Biol 2010;36:1644-1652.

22. Damron TA, Beauchamp CP, Rougraff BT, Ward WG Sr. Soft-tissue lumps and bumps. Instr Course Lect 2004;53:625-637.

23. Choi JY, Hong SH, Yoo HJ, Kim SJ. Musculoskeletal application of ultrasound elastography: soft tissue lipoma. J Korean Soc Ultrasound Med 2010;29:241-245. 